\title{
Pasting, morphological and functional properties of breadfruit (Artocarpus altilis) starch cross- linked with ethylene glycol dimethacrylate
}

\author{
Kehinde.N. Awokoya ${ }^{1 *}$, Vincent .O. Oninla ${ }^{1}$, Adeola .A. Ibikunle ${ }^{2}$, Adewale .O. Adebanjo ${ }^{2}$, \\ Abimbola .O. Okunniyi ${ }^{1}$ and Bridget. A. Moronkola ${ }^{3}$ \\ ${ }^{1}$ Department of Chemistry, Obafemi Awolowo University, Ile-Ife, Osun State,Nigeria. \\ ${ }^{2}$ Department of Chemical Sciences, Olabisi Onabanjo University, Ago-Iwoye, Nigeria. \\ ${ }^{3}$ Department of Chemistry, Lagos State University, P.O.Box 001, LASU Post Office, Lagos, Nigeria \\ ${ }^{*}$ Corresponding Author Email: knawokoya@gmail.com
}

\begin{abstract}
A novel succinylated crosslinked starch was prepared by using ethylene glycol dimethacrylate (EGDMA) as a crosslinker. In this current research, the study was designed to investigate the influence of single and dual chemical modifications on functional, pasting and morphological properties of starch extracted from breadfruit. The extracted starch was chemically modified to produce succinylated (SST) and succinylated-crosslinked starches (SCT). Proximate analysis revealed that following modifications, SST starches retained higher moisture content compared to native starch, while SCT starch had lower moisture content. Crude protein, crude fibre, crude fat and total ash of the native starch reduced following succinylation but increased after crosslinking. Scanning electron microscopy (SEM) revealed that crosslinked granules were not uniformly distributed but formed some aggregates. The absorption bands of the carbonyl group at 1784 and $1716 \mathrm{~cm}^{-1}$.appeared in FTIR spectra. The result indicates that all forms of modificationreduced the water binding capacity of native breadfruit starch. Gelation studies revealed that crosslinked breadfruit starch had a superior gelating property than the succinylated and native starches. The values of 94.70 and $79.95{ }^{\circ} \mathrm{C}$ obtained for the pasting temperature of SST and SCT respectively were higher than corresponding value of $79.90^{\circ} \mathrm{C}$ listed for native starch. All forms of modification reduced peak viscosity, trough viscosity, breakdown viscosity and final viscosity of the native starch. Setback viscosity reduced after succinylation but increased in crosslinked derivative, indicating less syneresis is likely to take placewithin the starch helices.
\end{abstract}

Keywords: Breadfruit starch, Physicochemical properties, Succinic anhydride, Ethylene glycol dimethacrylate and Cross linking

\section{INTRODUCTION}

Starch is not only a staple food in human and animal diets, it is also used as a raw material in the food industry, as well as in paper, textile and other industries. It can be used either in its native form or after chemical or physical modifications (Lena, 2001). The source of starch varies all over the world and it depends on the tradition and prevailing climatic conditions. It is the main energy component of most staple foods, including cereal grains (wheat, maize, barley, rice, oats, sorghum, millets), roots and tuber (potato, cassava), tree crops (plantain, jackfruit, pandamus and breadfruit) (Daniel et al., 2007).
The breadfruit (Artocarpus altilis) is aremarkable food. Breadfruit has for long been a staple food in Pacific islands, from where it spread to the Caribbean and Africa (Taylor and Tuia, 2007). It is known to be one of the highest yielding food plants, with a single tree producing up to 200 or more grapefruit-sized fruits per season (Balock and Cox, 1996). The fruit is round or ovoid, 3-8 in. in diameter, and weighs between 2 and $101 \mathrm{~b}$ (Kennard and Winters, 1960). It has been reported that breadfruit yields in terms of food are superior to other starchy staples such as cassava and yam (Singh, 2009). 

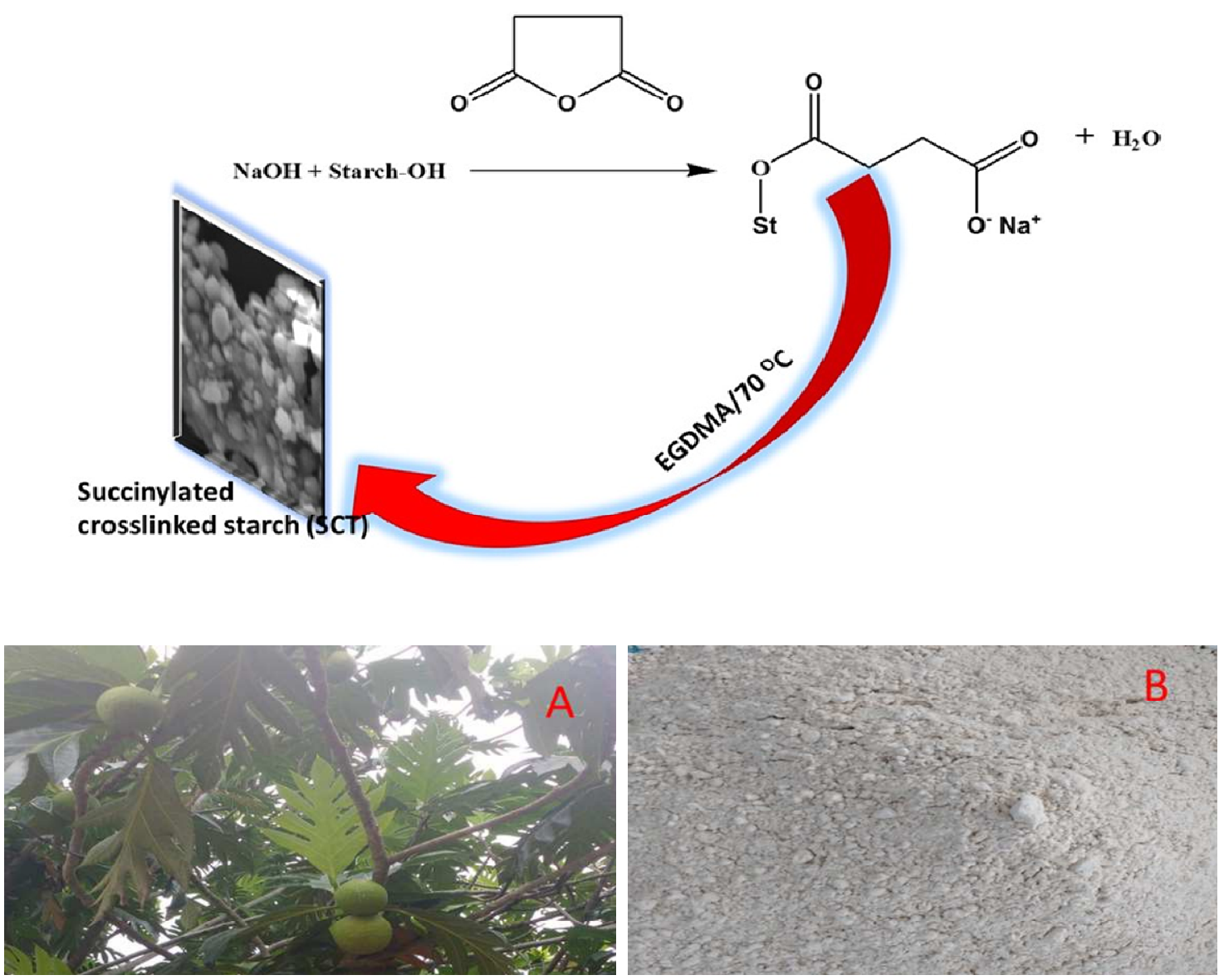

Figure1.Photographs of breadfruit tree with seeds(A) and breadfruit starch (B)

The mature fruit is a good source of carbohydrate (84\%) with starch constituting more than $60 \%$ of the total carbohydrate (Oladunjoye et al., 2010).

It is obvious that different starches have different physicochemical and functional characteristics. Some of these may be desirable whereas others make them unsuitable forspecific applications. So attempts have been made to modify the starches so that the undesirable properties are eliminated while the desirable ones are retained. Themodifications can be achieved by different techniques which include physical andchemical treatments and biotechnological techniques (Moorthy, 2002).

Studies on the modification of breadfruit starch involving heat-moisture-treatment and annealing, as forms of physical modification collectively referred to as hydrothermal treatment which entail modification of temperature and moisture content been carried out (Adebowale et al., 2005). Chemical modifications of some edible starches (breadfruit starch inclusive) through specific oxidizing agents such as sodium hypochlorite and hydrogen peroxide have also been reported (Forssell et al., 1999; Konoo et al., 1996).
In view of the availability of a large number of hydroxyl groups in the starch molecules, it is possible toprepare a large number of derivatives. The most common chemical derivatisation.

Include esterification, etherification and cross linking. These alter the starch propertiessignificantly depending on the level of modification and the nature of the derivative. Therefore, the study was designed to examine the physicochemical properties of native and chemically dual modified starch of breadfruit, with a view of producing hydrogels that have an improved functional, pasting, morphological, and structural properties which could be used for diverse purposes. To the best of our knowledge, this was the first time starch isolated from breadfruit would be dual modified using EGDMA

\section{MATERIALS AND METHODS}

\section{Materials}

Freshly harvested matured but unripe fruits of breadfruit (Artocarpus altilis) were collected from Ife-Warain Ife kingdom, Osun State, Nigeria. All chemicals used 
010 Afr. J. Food Sci. Technol.

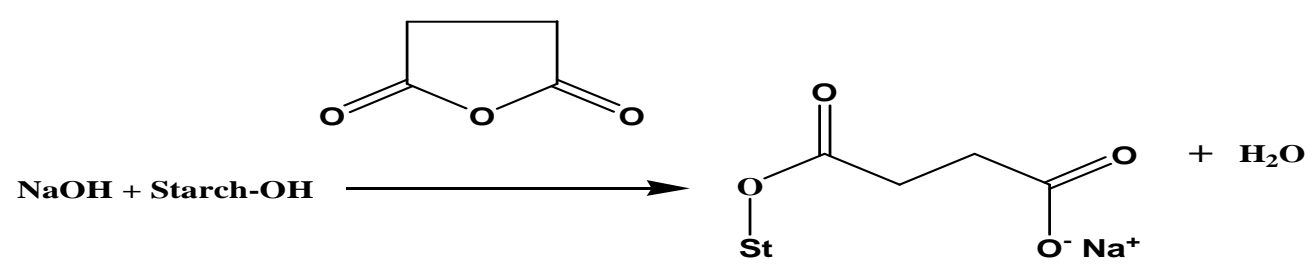

Scheme 1. Reaction of starch with succinic anhydride

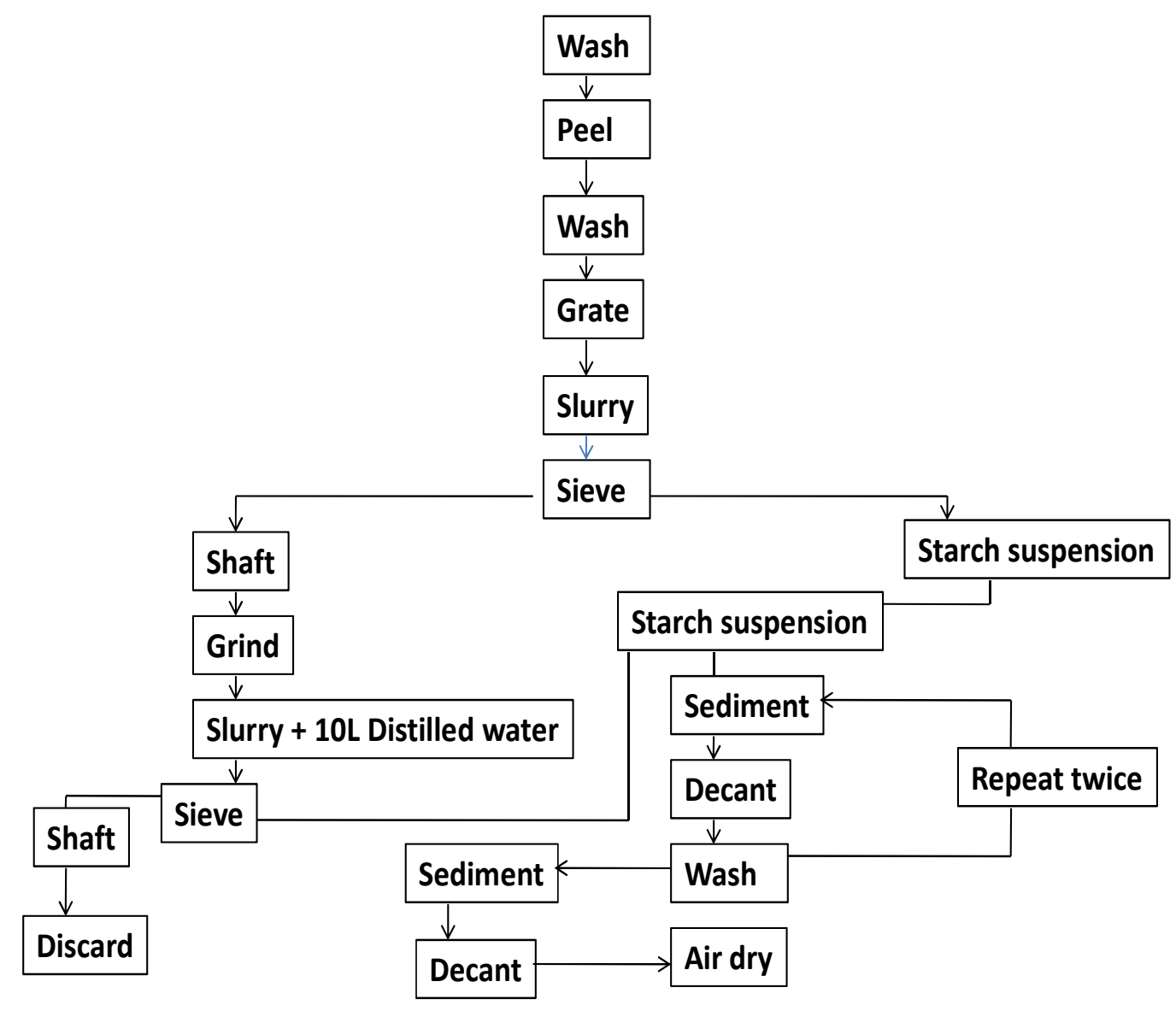

Figure2. Schematic diagram for extraction of breadfruit (Artocarpus altilis).

starch extraction and modifications were of analytical grade.

\section{Starch extraction from breadfruit}

Breadfruit starch was isolated using the method described by Agboola et al. (1990) with some modifications in drying time, drying method, sifting and sedimentation time. The method employed for starch isolation is outlined in Figure. 2. Peeled breadfruits $(20$ $\mathrm{Kg}$ ) werewashed thoroughly and grated. The grated pulp was suspended in 5 litres of distilled water for $4 \mathrm{~h}$ to allow the starch to come out of the pulp. The suspended pulp was sieved using a muslin clothe with retained fibre. The fibre was rewashed to remove adhering starch. The extracted starch was allowed to sediment for $12 \mathrm{~h}$, the supernatant was decanted off and the starch was washed with 10 litres of distilled water twice to remove proteins and fibre and finally sedimented for another $12 \mathrm{~h}$. The 
supernatant was then decanted. The obtained wet starch was sun dried for about 3 days, after which it was ground to fine powder using a mortar and pestle, and then stored in a closed vial for analysis.

\section{Breadfruit starch yield}

Starch yield was derived using Equation 1:

Starchyield $\%=\frac{\text { Weight of starch }(g)}{\text { Weight of edible portion }} \times 100$

\section{Synthesis of starch succinate}

The method of sathe and salunkhe (1981) was used with slight modification in $\mathrm{pH}$. Starch $(100 \mathrm{~g})$ was dispersed in $300 \mathrm{ml}$ ofdistilled water and stirred magnetically for $1 \mathrm{hr}$. The $\mathrm{pH}$ of the slurry was adjusted to $\mathrm{pH}$ 9.0using $1 \mathrm{M}$ $\mathrm{NaOH}$. Different amount of succinic anhydride (3, 6, and $9 \mathrm{~g}$ ) were used to treat the starch suspension (to obtain starch succinate of three different degrees of substitution) over aperiod of $2 \mathrm{~h}$ while maintaining a $\mathrm{pH}$ range of $8.0-$ 9.0. These succinylated starches were designated as SST-3, SST-6, and SST-9. At the end of the reaction the $\mathrm{pH}$ of theslurry was adjusted to $\mathrm{pH} 4.0$ using $0.5 \mathrm{M} \mathrm{HCl}$. The mixture was filtered, and the modified starch washed six times with distilled water and air dried for $36 \mathrm{~h}$.

\section{Dual modification using EGDMA (crosslinked)}

Another freshly prepared succinylated starch using $9 \mathrm{~g}$ of succinic anhydride was done using the above mentioned procedure. $30 \mathrm{~g}$ succinylated starch was solubilized in 20 $\mathrm{ml}$ ofdistilled water and stirred magnetically for $30 \mathrm{~min}$ at room temperature. To effect crosslinking, the slurry was heated at $70{ }^{\circ} \mathrm{C}$ with the addition of $10 \mathrm{ml}$ of EGDMA under vigorous stirring on a heating/stirring module.The sudden increase in viscosity of the system after $15 \mathrm{~min}$ showed the end of the reaction. The obtained succinylated crosslinked starch was transferred to Petri dish and oven dried at $40{ }^{\circ} \mathrm{C}$. The succinylated crosslinked starch was designated SCT-9. The SCT-9 was ground with a mortar and pestle and stored in a closed vial for further analysis.

\section{Determination of degree of modification}

The method of alkali sapanification as described by Genung and Mallatt (1941) was employed forthe determination of succinyl content. A sample $(1 \mathrm{~g})$ was weighed into a conical flask, $50 \mathrm{~mL}$ of $75 \% \mathrm{EtOH}$ was added, and the mixture was refluxed for $30 \mathrm{~min}$ while maintaining a temperatureof $50{ }^{\circ} \mathrm{C}$. After cooling to room temperature, $40 \mathrm{~mL}$ of $0.5 \mathrm{M} \mathrm{NaOH}$ was added. The flask was covered with aluminium foil and allowed to stand at room temperature for $72 \mathrm{~h}$ with occasionalshaking. Saponification occurred with the addition of $\mathrm{NaOH}$, and the excess alkali was determined by titrating with $0.5 \mathrm{M}$ $\mathrm{HCl}$ using phenolphthalein indicator. Native starch was treatedin the same manner to obtain a value for the blank. The percentage of succinyl group and the degree of substitution of the samples calculated using Eq. 2 and 3 respectively.

$$
\begin{aligned}
& \% \text { Succinyl } \\
& =\frac{(\text { Blanktitre }- \text { sampletitre }) \times 0.1 \times \text { molarityofacid } \times 100}{\text { Weight of the sample }(\mathrm{g})}
\end{aligned}
$$

Degree of Substitution (DS)

$$
=\frac{162 \times \% \text { Succinyl }}{1000-(99 \times \% \text { Succinyl })}
$$

The reaction efficiency (RE) was calculated as follows:

$$
R E=\frac{\text { Actual DS }}{\begin{array}{c}
\text { Theoretical DS } \\
\times 100 \%
\end{array}}
$$

The theoretical DS was calculated assuming that all of the added succinic anhydride reacted with starch to form the ester derivative

\section{Proximate analysis}

Standard Association of Official Analytical Chemistry methods (AOAC 1984), wereadopted for estimating moisture content, total ash, crude protein, crude fat, crude fibre and carbohydrate.

\section{Physicochemical properties}

\section{Least gelation studies}

The method of Coffman and Garcia (1977) was employed with slight modification. Starch dispersions $(2-18 \% \mathrm{w} / \mathrm{v})$ were prepared in test tubes with distilled water $(5 \mathrm{ml})$. The starchsuspensions were thoroughly mixed for $5 \mathrm{~min}$. The test tubes were heated for $30 \mathrm{~min}$ at $70^{\circ} \mathrm{C}$ in awater bath, followed by rapid cooling under running cold tap water for 2 h. Least gelation concentration was determined as lowest concentration when the sample from the inverted testtube did not fall down or slip.

\section{Scanning electron microscopy (SEM)}

To determine the surface morphology of the native and modified starches, each starch granulewere taken and dustedonto a carbon sticker, then coated with gold using a sputter coater (Balzers Union, FL-9496) for $30 \mathrm{~min}$. Images were recorded using concise FEGSEM 6100 
Table 1.Proximate composition of native and modified starches of breadfruit.

\begin{tabular}{llrrrrc}
\hline Starch & Protein (\%) & Fat (\%) & Fibre (\%) & Ash (\%) & Moisture (\%) & Carbohydrate (\%) \\
\hline NATIVE & 1.07 & 0.42 & 1.11 & 1.26 & 12.67 & 83.47 \\
SST3 & 0.97 & 0.38 & 0.92 & 1.21 & 12.93 & 83.59 \\
SST6 & 0.8 & 0.29 & 0.85 & 1.14 & 13.28 & 83.58 \\
SST9 & 0.79 & 0.25 & 0.81 & 1.09 & 13.69 & 83.37 \\
SCT & 91.12 & 0.46 & 1.15 & 1.34 & 12.54 & 83.39 \\
\hline
\end{tabular}

All values are means of triplicate determinations

Zeiss Ultra Plus Germany at an accelerated voltage of $20.0 \mathrm{kV}$ with secondary electrons in low vacuum mode (LV).

\section{Fourier transform infrared (FT-IR) spectroscopy}

The Fourier transform infrared spectra of the native and modified starches were obtainedusing a Perkin-Elmer Spectrum 100 FT-IR spectrometer Walth man, (MA, USA) with an Auto IMAGE System in the frequency range $4000-400 \mathrm{~cm}^{-1}$.

\section{Water binding capacity (WBC)}

This was carried out using the Medcaf and Gillies method (1965). $37.5 \mathrm{ml}$ of distilled water was addedinto $2.5 \mathrm{~g}$ of the breadfruit starch (modified and the native) and was centrifugedfor 10 minutes at $3000 \mathrm{rpm}$. Then the weight of thecentrifuge tube and content was determined afterdecanting the water and allowed todrain for another10 minutes. The bound water was determined by thechange in weight. It was calculated by Eq. 5 .

Water binding capacity

$$
=\frac{\text { Boundwater }(\mathrm{g})}{\text { Weightofsample }(\mathrm{g})} \times 100
$$

\section{Pasting characteristics}

The pasting characteristics of native, modified and crosslinked starches were determined using a Rapid Visco Analyser Super 4 model (RVA).The moisture content of the sample was first determined to obtain the correct sample weight and amount of water required for the test. An aqueous suspension of sample was made by dispersing fifteen grams (dry basis) of starch in $25 \mathrm{~mL}$ distilled water. A programmed heating and cooling cycle was employed at constant shear rate, where the sample was held at $50^{\circ} \mathrm{C}$ for $1 \mathrm{~min}$, heated to $95^{\circ} \mathrm{C}$ in $3 \mathrm{~min}$ and then held at $95{ }^{\circ} \mathrm{C}$ for $2 \mathrm{~min}$. It was subsequently cooled to $50{ }^{\circ} \mathrm{C}$ within $3 \mathrm{~min}$ and then held at $50{ }^{\circ} \mathrm{C}$ for 2 min.Readings were displayed on the monitor in a numerical and graphical form. Viscosities were expressed in centipoises.

\section{RESULTS AND DISCUSSION}

\section{Breadfruit starch yield}

The reason for this analysis is to quantify the extractable starch in the breadfruit. The percentage extractable starch yield obtained from the breadfruits used in this study was $3.19 \%$, which is less than $14.26 \%$ reported by Akanbi et al. (2009)and $15.40 \%$ reported by Onwueme (1978). Nonetheless, the reduction compared to others that have been reported might have happened during the starch isolation process. In addition, it is also reasonable to expect variation in the starch contents because all breadfruits regardless of their origin, have different maturity stage, variety, climatic and agronomic conditions (Rahman et al., 1999).

\section{Proximate composition of breadfruit starch}

The results of the crosslinked, modified and native breadfruit starch (NATIVE) presented in Table 1 indicates increase in moisture content following succinylation and reduction in moisture content after dual modification (crosslinked). The moisture content of the starches ranged between $12.54 \%$ and $13.69 \%$. Among the pnodified starches, SST 9 had the highest moisture content, while the least moisture height was noticed in crosslinked starch (SCT 9). The moisture content of all starches reported in this work was higher than the moisture contents of the breadfruit pulp and whole flour of $11.42 \%$ and $7.78 \%$ reported by Gbadamosi et al.(2011). The crude protein, crude fibre, crude fat and total ash of the native starch reduced following succinylation but increased after crosslinking. Reductions observed in the ash, protein, fat and fibre contents could be attributed to structural collapse of the starch molecule and losses during chemical modification processes. Similar observation has been reported by Lawal (2004).On the other hand, introduction of the crosslinking monomer (EGDMA) on starch succinate probably accounts for increase in ash, protein, fat and fibre contents as observed.The carbohydrate content of the starches was between $83.37 \%$ and $83.59 \%$, which were higher than those reported by Koh and Kong (2012). 
Table 2.Effects of increasing concentration of succinic anhydride on \% succinyl, DS and RE of breadfruit starch.

\begin{tabular}{l|c|c|c}
\hline Succinic anhydride & \% succinyl & DS & RE \\
\hline NATIVE & 0.00 & 0.00 & 0.00 \\
SST 3 & 1.65 & 0.32 & 10.67 \\
SST 6 & 2.10 & 0.43 & 14.33 \\
SST 9 & 3.05 & 0.71 & 23.67 \\
\hline
\end{tabular}

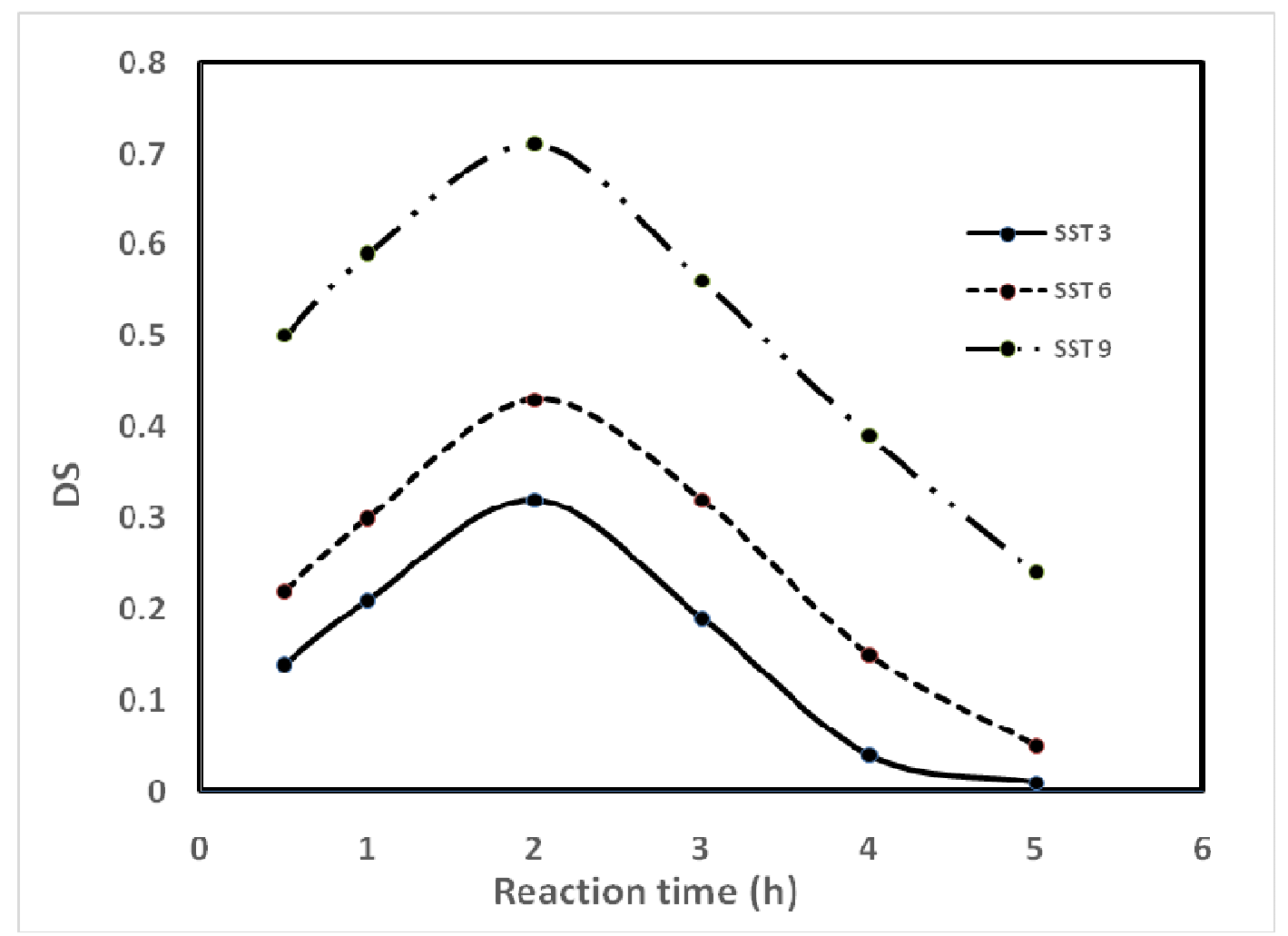

Figure 3. Effect of reaction time on DS at different concentrations of succinic anhydride.

\section{Succinyl (\%) and Degree of modification}

Succinylation is considered as an ideal modification since it provides starch derivatives with desirable properties. The effect of increasing concentration of succinic anhydride on \% succinyl, DS and RE of the breadfruit starch is shown in Table 2.Adding succinic anhydride and $\mathrm{NaOH}$, as a base catalyst,to starch molecule eventuated in succinylation of the starch. The range of succinyl content and DS achieved in this study were around $1.65-3.05 \%$ and $0.32-0.71$ respectively. The results showed that an increase in the concentration of the acylating agent from 3 to $9 \mathrm{~g}$ gave a substantial increase in \% succinyl, DS and RE.The succinylated starch with the highest concentration of succinic anhydride $(9 \mathrm{~g} / 100 \mathrm{~g})$ presented higher \% succinyl, DS and RE as compared with starches succinylated with $3 \mathrm{~g}$ and $6 \mathrm{~g} / 100 \mathrm{~g}$ succinic anhydride. This may be attributed to an increased rate of contact of the acylating agent with the starch molecules, which opened the structure of the granule, and facilitated proximity and physical access of succinic anhydride to the inner helix of the granule. This observed behaviour is convenientlyin agreement with the earlier report for maize starch by Lawal (2004).

\section{Influence of reaction time on esterification}

Figure. 3 demonstrates the effect of reaction time on DS for concentrations of succinic anhydride equal to 3\%,6\% and $9 \%(\mathrm{w} / \mathrm{w})$. The DS values of all the starches increased progressively as the concentration of the succinic anhydride increases from $3 \%$ to $6 \%$ at $2 \mathrm{~h}$ 
014 Afr. J. Food Sci. Technol.

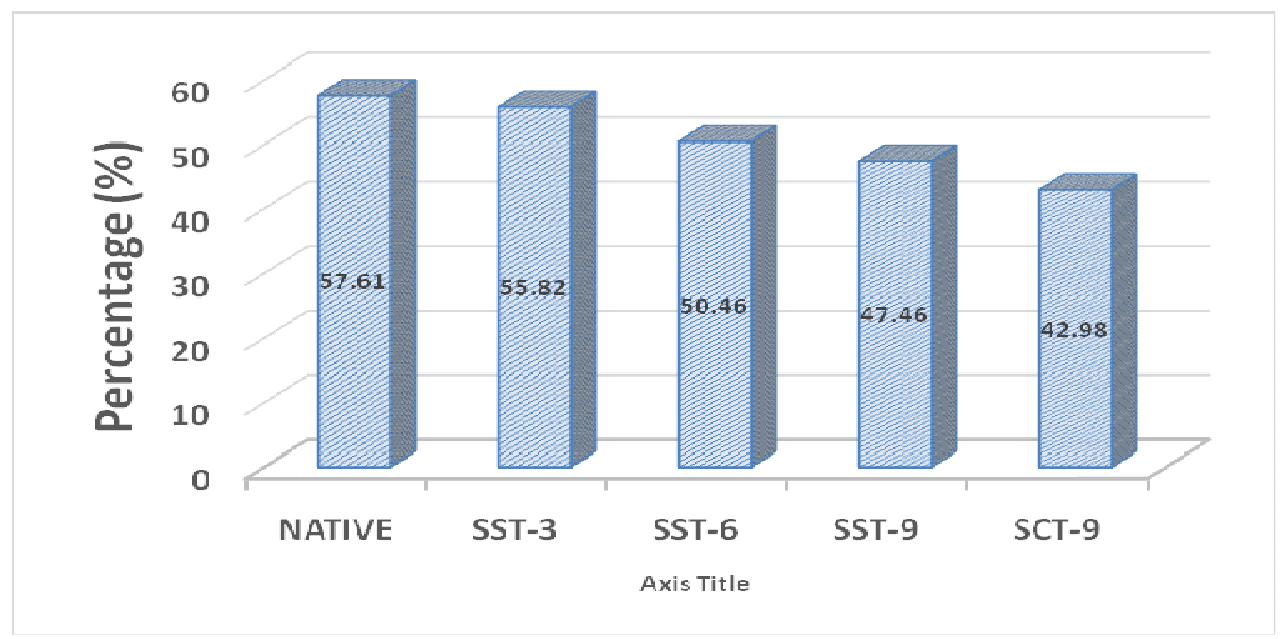

Figure 4. Water binding measurements of native, single and dual (crosslinked) modified starches.

Table 3.Pasting properties of native, crosslinked and representative of modified starches of breadfruit

\begin{tabular}{llcc}
\hline \multicolumn{3}{c}{ Starch sample } & \\
\cline { 2 - 4 } & NATIVE & SST 9 (modified) & SCT 9 (crosslinked) \\
\hline PV (cP) & 5326 & 226 & 3552 \\
TV (cP) & 4330 & 78 & 3450 \\
BV (cP) & 996 & 148 & 102 \\
FV (cP) & 6644 & 155 & 5827 \\
SV (cP) & 2314 & 77 & 2377 \\
P & 79.90 & 94.70 & 79.95 \\
\hline
\end{tabular}

PV, Peak viscosity; TV, trough viscosity; BV, breakdown viscosity; FV, final viscosity; SV, setback viscosity; $\mathrm{P}_{\text {Temp, }}$ pasting temperature. Values are means of duplicate determinations.

reaction time.A Further increase in the succinic anhydride concentration up to $9 \%$ also increased the DS at $2 \mathrm{~h}$ reaction time. Overall, the DS values increased with increase in reaction time from $0.5 \mathrm{~h}$ to $2 \mathrm{~h}$. However, increasing the reaction time beyond $2 \mathrm{~h}$ impacted negatively and resulted in a steady decrease in DS for all the starches. This reduction in DS with timecould be due to the hydrolysis and chemical reassociation of the starch succinate. Thus, optimum reaction time of $2 \mathrm{~h}$ was used in this work.

\section{Water binding property}

The water binding property of the native, modified and crosslinked starches was investigated to study their hydrophilic property (Figure. 4). Water binding capacity is the ability of starch molecule to entrap water and swell for improved consistency in food. The results showed that the highest binding capacity was found in the native starch and the least binding capacity was found in the crosslinked starch (SCT-9). The least water binding capacity observed in thecrosslinked starch might be due to the complex architecture network formed by high amounts of interchained linkages between starch and ethylene glycol dimethacrylate. These linkages weakened the docility and flexibility of the starch matrix which is unfit for hydrophilicity. In addition, water binding pattern decreased as concentration of succinic anhydride increases (SST-3 to SST-9). The result indicates that all forms of modification (single and dual) reduced the water binding capacity of native breadfruit starch.The water binding capacity value obtained for the native breadfruit starch was $57.61 \%$, which is far higher than $8.26 \%$ reported by Akanbi et al. (2009) and slightly higher than $53.00 \%$ reported by Adegunwa et al. (2014). These results suggest that breadfruit starch may find application in food systems as substitute for dough food product such as pounded yam.

\section{Pasting properties}

The assessment of the viscosity over heating-cooling cycles by the RVA provided valuable information on the transition from a suspension of starch granules to a paste. Pasting properties of native, modified and crosslinked starch samples are presented in Table 3 . After succinylation and crosslinking, gelatinization temperature $\left(\mathrm{P}_{\mathrm{T}}\right)$ of native starch is increased. In 


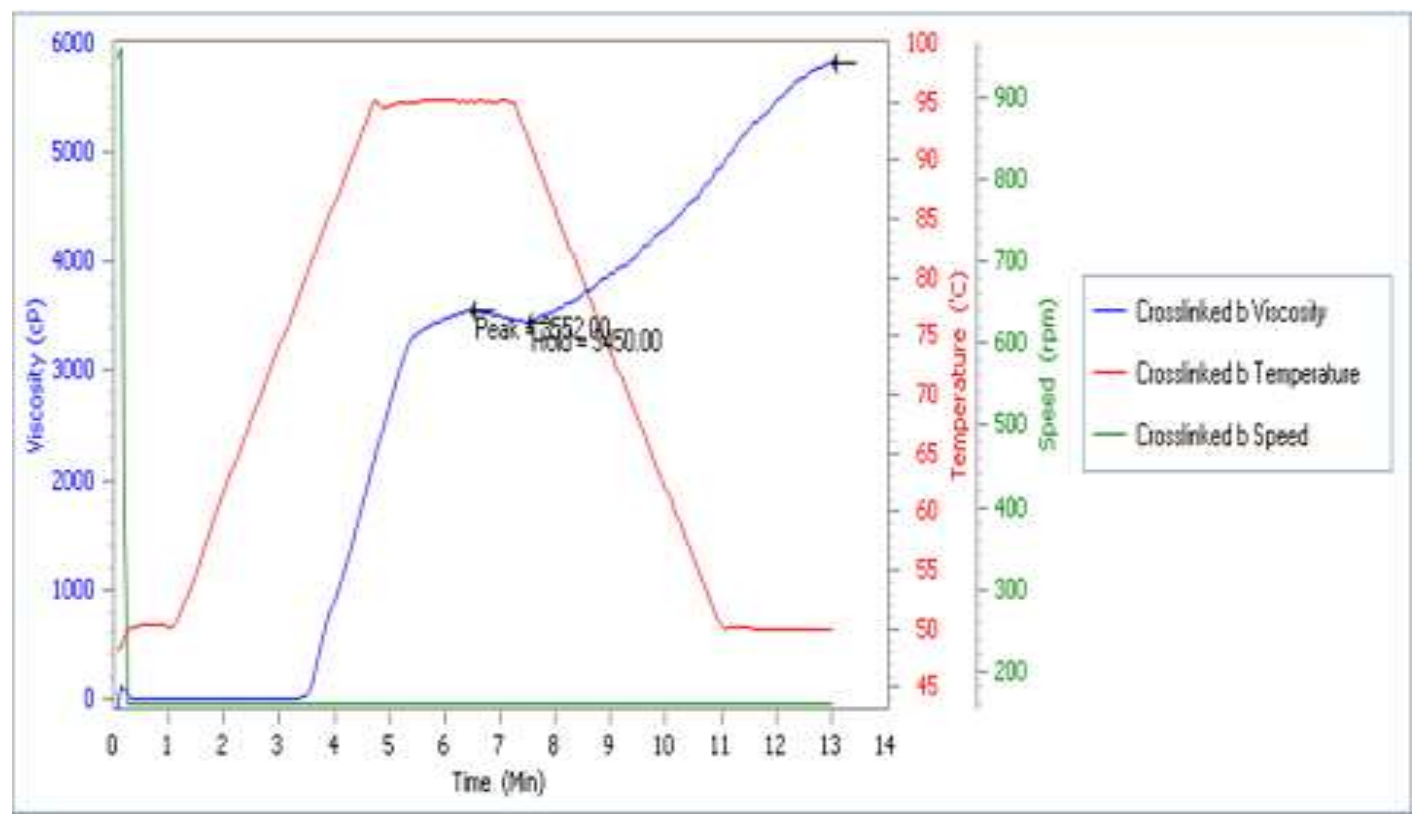

Figure 5. Rapid visco analyzer pasting profile of crosslinked breadfruit starch

Table 4.Gelation properties of native, modified and crosslinked starch derivatives of breadfruit

\begin{tabular}{|c|c|c|c|c|c|}
\hline \multirow[t]{2}{*}{ Concentration (\% w/v) } & \multicolumn{5}{|c|}{ Starch sample } \\
\hline & Native & SST 3 & SST 6 & SST 9 & SCT 9 \\
\hline 2 & - Liquid & - Liquid & - Liquid & - Liquid & - Liquid \\
\hline 4 & - Liquid & - Liquid & - Liquid & - Liquid & - Liquid \\
\hline 6 & - Liquid & - Liquid & - Liquid & - Liquid & - Liquid \\
\hline 8 & - Liquid & - Liquid & - Liquid & - Liquid & - Liquid \\
\hline 10 & - Liquid & - Viscous & - Liquid & - Liquid & - Viscous \\
\hline 12 & -Liquid & -Viscous & - Liquid & -Liquid & + Gel \\
\hline 14 & $+\mathrm{Gel}$ & + Gel & -Viscous & $+\mathrm{Gel}$ & + Gel \\
\hline 16 & +Firm gel & + Gel & + Gel & $+\mathrm{Gel}$ & + Gel \\
\hline 18 & +Firm gel & +Firm gel & +Firm gel & +Firm gel & +Firm gel \\
\hline $\mathrm{LGC}^{\mathrm{a}}$ & 14 & 14 & 16 & 14 & 12 \\
\hline
\end{tabular}

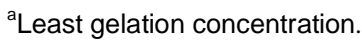

contrast, peak viscosity, trough viscosity, breakdown viscosity and final viscosity of the native starch reduced after all forms of derivatization. Peak viscosity is the maximum viscosity attained during or immediately after cooking is an indication of paste strength formed from gelatinization during processing(Adebowale et al., 2011).The decrease in peak and trough viscosities following succinylation and crosslinking may be caused by partial cleavage of the glycosidic linkages from esterification resulting in a decrease in chain length of starch molecules. Also, Adebowaleet al(2005) have reported reduced peak viscosity of breadfruit starch after acetylation and oxidation.It is also worth noting that the crosslinked starch exhibited substantial higher peak and trough viscosities (3552 and $3450 \mathrm{cP}$ ) (Table 3 and Figure 5) when compared to the modified starch (226 and $78 \mathrm{cP})$. This observation can be explained by the crosslinking of molecular granular chains that makes the starch granules more ordered and thus have higherpeak and trough viscosities. The results also indicate a significant reduction in setback value of the native starch after modification, whereas increase was observed in the setback viscosityafter crosslinking. This is probably as a result of retrogradation which is usually accompanied by a series of physical changes such as increased viscosity and turbidity of pastes.

\section{Gelation properties}

Using the least gelation concentration (LGC) as the index of gelation capacity, the gelation properties of native, modified and crosslinked starch is presented in Table 4. The lower the LGC, the better the gelating property of the 


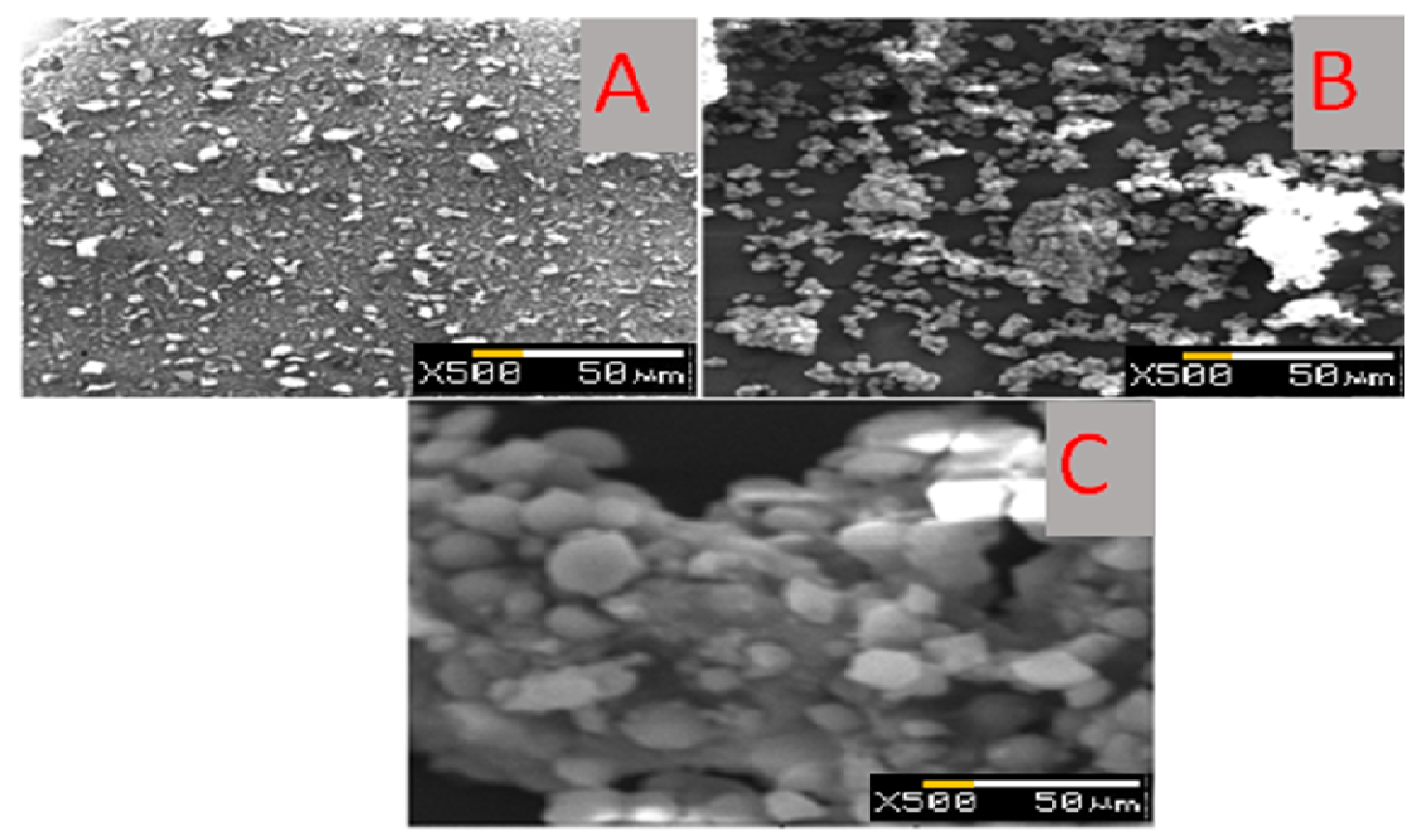

Figure 6. Scanning electron micrographs of native (A), representative of modified (B), and crosslinked $(C)$ breadfruit starches

starch.Among the starches, SCT 9 had the least LGC of 12, while highest value, 16, was observed in SST 6. Native, SST 3, and SST 9 starch had LGC value of 14 but at $12 \% \mathrm{w} / \mathrm{v}$, SST 3 starch appeared viscous while both native and SST 9 starch remained liquids. Starch granules swell during the process of gelatinization to build a globular network. The swelling of the granules is important to maintain structural rigidity of the starch and to facilitate gel formation. The reduction in concentration and superior gelating property observed in the crosslinked (SCT 9) starch could be attributed to strength and stability of hydrogen bonds caused by the introduction of carbonyl and carboxyl groups. This result agrees with observations reported by Pereira et al (2017), who oxidized oat starch with hydrogen peroxide and reported that the least concentration of starch for gel formation was $9 \%$, while for native starch was $12 \%$.

\section{Granule SEM morphology}

Scanning electron micrographs of native, representative of modified and crosslinked starches from breadfruit are presented in Figure. 6. SEM investigations showed that the treatment of the starch molecule with succinic anhydride and EGDMA caused some significant changes in the structure of starch granules as compared with the native starch. Native breadfruit starch has smooth appearance with some forms of well dispersed uniform granule size. Compared with the native starch, the surface of modified starch granule becomes rougher.
SEM image of the crosslinked starch indicates that granules were not uniformly distributed but formed some aggregates. Thus, when starch chains are crosslinked, they tend to entangle with each other and this makes it difficult for any individual chain to move easily, resulting in the formation of aggregates. Furthermore, it is expected that the modifier will form an ester bond with the hydroxyl groups on starch molecule. However, because of the multi-reactive sites of the hydroxyl groups on starch molecule, there must be some unreacted sites on the succinylatedgranule chains. When EGDMA is added, these unreacted sites on the chain will further react with EGDMA via hydrogen bonding to crosslinked the starch molecule which probably accounts for the aggregationsobserved in figure $6 \mathrm{C}$.

\section{Infrared spectra}

The FT-IR spectra of native, representative of modified and crosslinked starches of breadfruit are

depicted in Figure. 7.The spectrum of all the samples shows the presence of various functional groups. The fingerprint region, which is between 600-1400 cm ${ }^{1}$ contains complicated series of absorptions for each different spectrum. The strong broad bands appearing at 3404,3410 and $3394 \mathrm{~cm}^{-1}$ were due to the $\mathrm{O}-\mathrm{H}$ stretching in native, modified and crosslinked starches respectively.Both modified and crosslinked starch spectra show new absorption bands at 1784 and $1716 \mathrm{~cm}^{-1}$. With these new bands, it is confirmed that succinylation and 

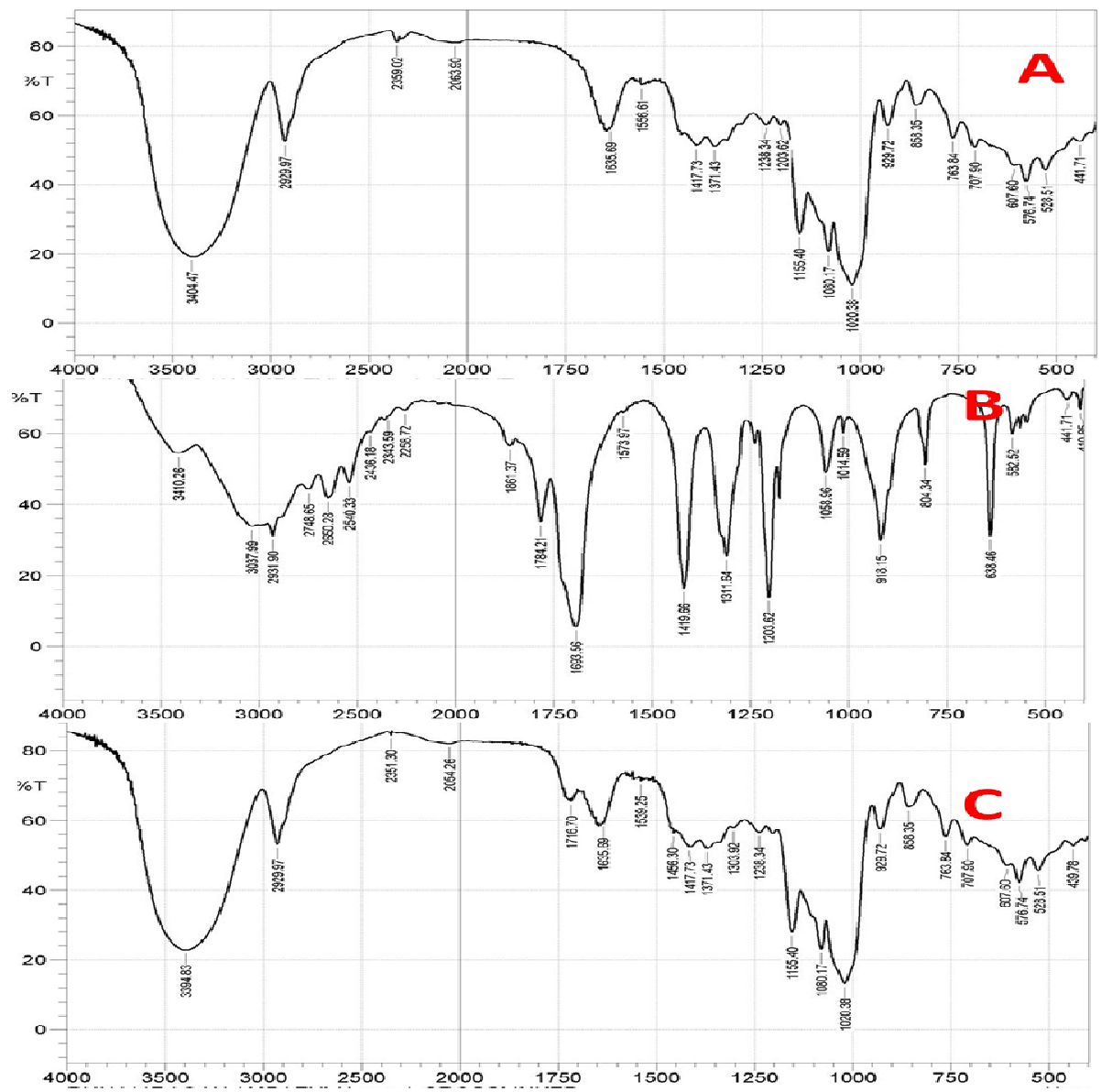

Figure 7. FT-IR spectra of native (A), representative of modified (B), and crosslinked (C) breadfruit starches.

crosslinking had taken place. Moreover the stretching frequencies at 1417,1419 and $1456 \mathrm{~cm}^{-1}$ in thespectra $7 \mathrm{a}, 7 \mathrm{~b}$ and $7 \mathrm{c}$ respectively were indicative of carbon single bonded hydroxyl group. The peaks at $441-858 \mathrm{~cm}$ ${ }^{1}$ were fromC-H out of plane bending vibration, which were found in all the spectra. There are appearances of several additional peaks between 2748 and $2929 \mathrm{~cm}^{-1}$ in all the spectra, which can be ascribed to stretching vibration of $\mathrm{C}-\mathrm{H}$. Generally, the spectra data revealed broadening or reduction of peaks after the process of esterification.

\section{CONCLUSIONS}

Succinylated crosslinked granule and starch succinates with a high degree of substitution were synthesized by a method in which breadfruit starch reacted with succinic anhydride using EGDMA as an effective crosslinking agent.Based on the results, it can thus be deduced that the starch produced from breadfruit can be altered through succinylation and crosslinking. The DS values increased with increase in reaction time from $0.5 \mathrm{~h}$ to $2 \mathrm{~h}$. However, reaction time beyond $2 \mathrm{~h}$ resulted in a steady decrease in DS for all the starches. The absorption bands of the carbonyl group at 1784 and $1716 \mathrm{~cm}^{-1}$.appeared in FTIR spectra.SEM investigations showed that the treatment of the starch molecule with succinic anhydride and EGDMA caused some significant changes in the structure of starch granules as compared with the native starch Thus it can be concluded that there is much scope for the use of this crosslinking agent to produce high quality starch that can effectively meet the functional properties demand for food applications.

\section{REFERENCES}

Adebowale KO, Olu-Owolabi BI, Olawumi EK, Lawal OS (2005) Functional properties of native, physically and chemically modified breadfruit (Artocarpusaltilis) starch. Industrial Crops and Products 21: 343-351

Adebowale AA, Sanni LO, Fadahunsi EL (2011). Functional and pasting properties of cassava-sweetpotato starch blends. Afr. J. Root Tuber Crop 9: 6-10

Adegunwa MO, Adebowale AA, Bakare HA, Ovie SG (2014). Compositional characteristics and functional properties of instant plantain-breadfruit flour. Int. Journal of Fd Research. 1: 1-7.

Adepeju AB, Gbadamosi SO, Adeniran AH, Omobuwajo TO (2011). Functional and pasting characteristics of breadfruit (Artocarpusaltilis) flours. African J. Food Sci. 5: 529-535 
Agboola SO, Akingbola JO, Oguntimi GB (1990). Processing of cassava starch for adhesives production. Starch/Starke 42: 12-15

Akanbi TO, Nazamid S, Adebowale AA (2009). Functional and pasting properties of a tropical breadfruit (Artocarpusaltilis) starch from lleIfe, Osun State, Nigeria. Int. Food Research Journal16: 151-157.

Association of Official Analytical Chemists (AOAC) 1984. Official Methods of Analysis. $15^{\text {th }}$ Edition, Washington D.C

Balick M, Cox P, (1996). Plants, People and Culture: The science of Ethnobotany. Scientific American Library HPHLP, New York

Coffman CW, Garcia VV (1977). Functional properties and amino acid content of a protein isolate from mung bean flour. J. Food Technol. 12: $473-476$

Daniel JR, Whistler RL, Harald R, Elvers B (2007). Starch In: Ullmann's Encyclopedia of Industrial Chemistry, John Wiley \& Sons, New York

Forssell HS, Myllärinen P, Moates G, Parker R (1999). Ageing of rubbery thermoplastic barley and oat starches. Journal of Carbohydrate Polymer: 39: 43-51

Genung L, Mallat R (1941).Analysis of Cellulose Derivatives:Determination of Total Combined Acyl in Cellulose Organic Esters. Ind. Eng. Chem., 13: $369-374$

Kennard WC, Winters HF, (1960). Some fruits and nuts for the tropics. Misc. Publication No. 801, U.S. Dept. Agric.: Washington, DC

Koh SP, Kong K (2012). Comparison of physical, chemical and functional properties of broken rice and breadfruit starches against cassava starch. J. Trop. Agric. and Fd. Sc. 40: 211-219.

Konoo S, Ogawa H, Mizuno H, Iso N (1996). The emulsifying ability of oxidized tapioca starch with sodium hypochlorite. $J$ of Japanese Soc. of Fd Sc. and Technology 43: 880-886

Lawal O.S (2004).Succinyl and acetyl derivatives of a hybrid maize: physicochemical characteristics and retrogradation properties monitored by differential scanning calorimetry. Carbohydrate Research 339: 2673-2682.

Lena Anderson, (2001).Studies on starch structure and the differential properties of starch branching enzymes. PhD Thesis, Swedish University of Agricultural Sciences

Medcalf DG, Gillies KA (1965). Wheat starches 1: Comparison of physicochemical properties. Journal of Cereal Chemistry 42: 558562

Moorthy SN (2002). Physicochemical and functional properties of tropical tuber starces- a review, starch/stärke 54: 559-592.
Oladunjoye IO, Ologhobo AD, Olaniyi CO (2010). Nutrient composition, energy value and residual anti-nutritional factors in differently processed breadfruit (Artocarpusaltilis) meal. Afr. J. Biotechnol. 9: 4259-4263

Onwuene IC (1978). The tropical tuber crops: yams, cassava, sweet potato, and cocoyam. Chiehester: John Wiley \& Sons, New York

Pereira JM, Evangelho JA, Moura FA, Gutkoski LC, Zavareze ER, Dias ARG (2017).Crystallinity, thermal and gel properties of oat starch oxidized using hydrogen peroxide. Int. Food Research J. 24: 15451552.

Rahman MA, Nahar N, Jabbar MA, Mosihuzzaman M (1999). Variation of carbohydrate composition of two forms of fruit from jack tree (Artacarpusheterophyllus) with different maturity and climatic conditions. Food chemistry 65: 91-97

Sathe SK, Salunkhe DK (1981). Functional propertiesd of great Northern bean (Phaseolus vulgaris) proteins: Emulsion, Foa,ming, Viscisity, and Gelation Properties. J. Food Sci. 46: 617 - 621

Singh H (2009). Tapping into breadfruit's bounty. Available online at http://www.universityaffairs.ca/tapping-into-breadfruits bounty.aspx. Accessed 22 Nov 2017

Taylor MB, Tuia VS (2007) Breadfruit on the pacific region. ActaHorticulturae (ISHS) 757: 43-50 